\title{
Erratum to "Is the Gut Microbiota a New Factor Contributing to Obesity and Its Metabolic Disorders?"
}

\author{
Kristina Harris, ${ }^{1}$ Amira Kassis, ${ }^{2}$ Geneviève Major, ${ }^{2}$ and Chieh J. Chou ${ }^{2}$ \\ ${ }^{1}$ Department of Nutritional Sciences, The Penn State University, 110 Chandlee Laboratory University Park, PA 16802, USA \\ ${ }^{2}$ Nutrition and Health Department, Nestlé Research Center, Route du Jorat 57, 1000 Lausanne, Switzerland
}

Correspondence should be addressed to Chieh J. Chou, chieh-jason.chou@rdls.nestle.com

Received 12 March 2012; Accepted 8 April 2012

Copyright (C) 2012 Kristina Harris et al. This is an open access article distributed under the Creative Commons Attribution License, which permits unrestricted use, distribution, and reproduction in any medium, provided the original work is properly cited.

Section 3.3.1. (page 3, starting from the second line from the bottom). In describing a series of experiments, the word "rats" was accidentally used in the place of "mice." The corrected sentences should read as follows. "In a study of genetically identical male mice, infusing a low level of LPS for 4 weeks caused the same amount of weight gain as a high-fat diet [33]. Mice that had a knockout of an immunoprotein (CD14), which is necessary to cause an inflammatory reaction to LPS, were immune to weight gain [33]. Together the data show that mice naturally prone to weight gain on a highfat diet have intestinal inflammation, inflammation alone can cause weight gain in normal rodents, and the absence of inflammation protects animals against weight gain from a high-fat diet."

Section 3.3.2. (page 4, first column, middle of first full paragraph). The corrections are in capital letters and sentence should read, "The latter effect is thought to be caused by REDUCED Fiaf production (Fasting-induced adipocyte factor or ANGPTL4) in the intestine of conventionalized mice AS COMPARED WITH THAT OF GF MICE [37]."

Figure 3. On the diagram of the two primary methods of LPS entry into circulation, "blood stream" should be "circulation." 


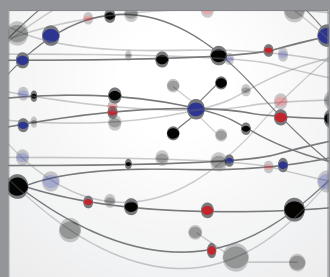

The Scientific World Journal
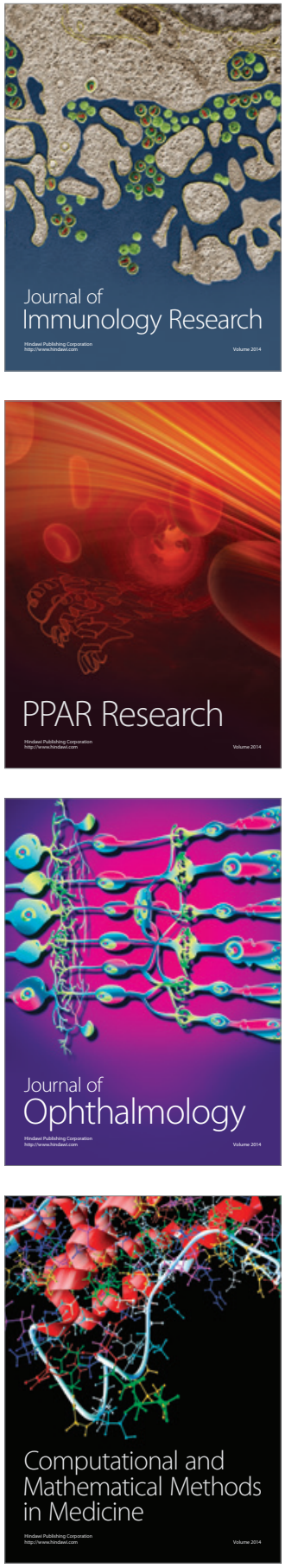

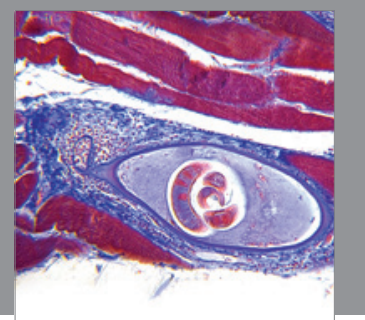

Gastroenterology

Research and Practice
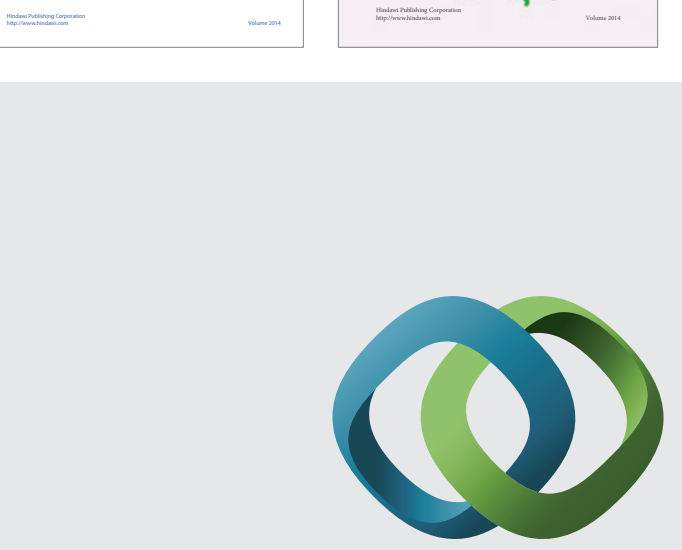

\section{Hindawi}

Submit your manuscripts at

http://www.hindawi.com
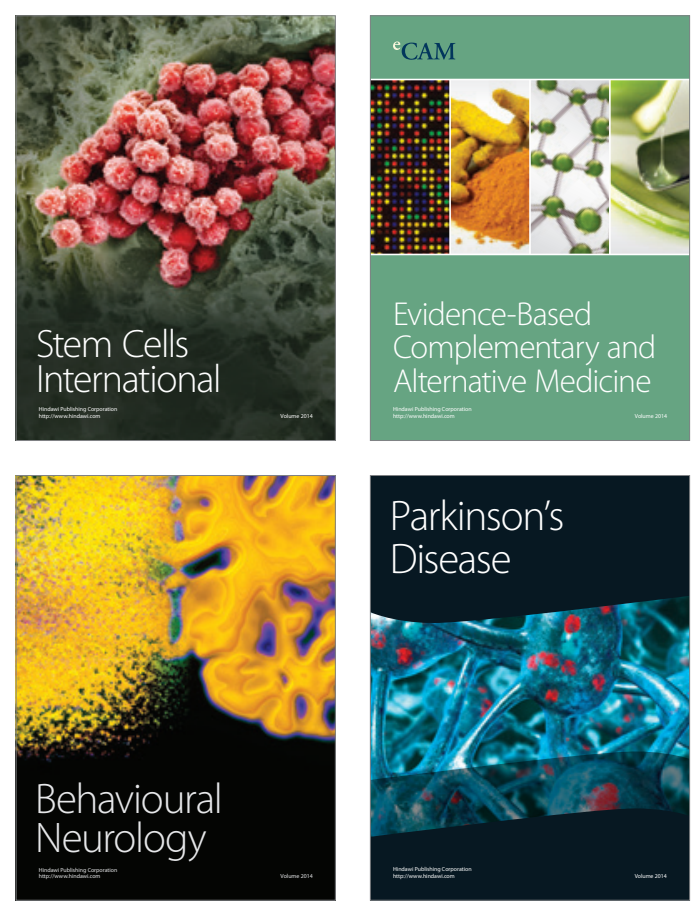

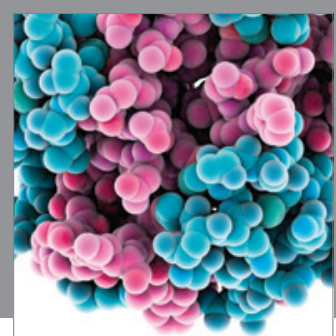

Journal of
Diabetes Research

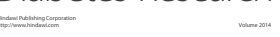

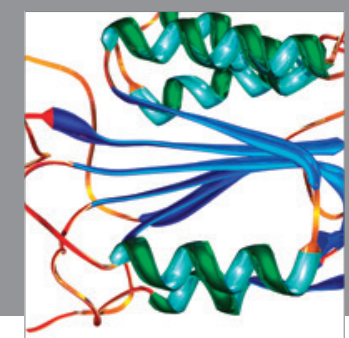

Disease Markers
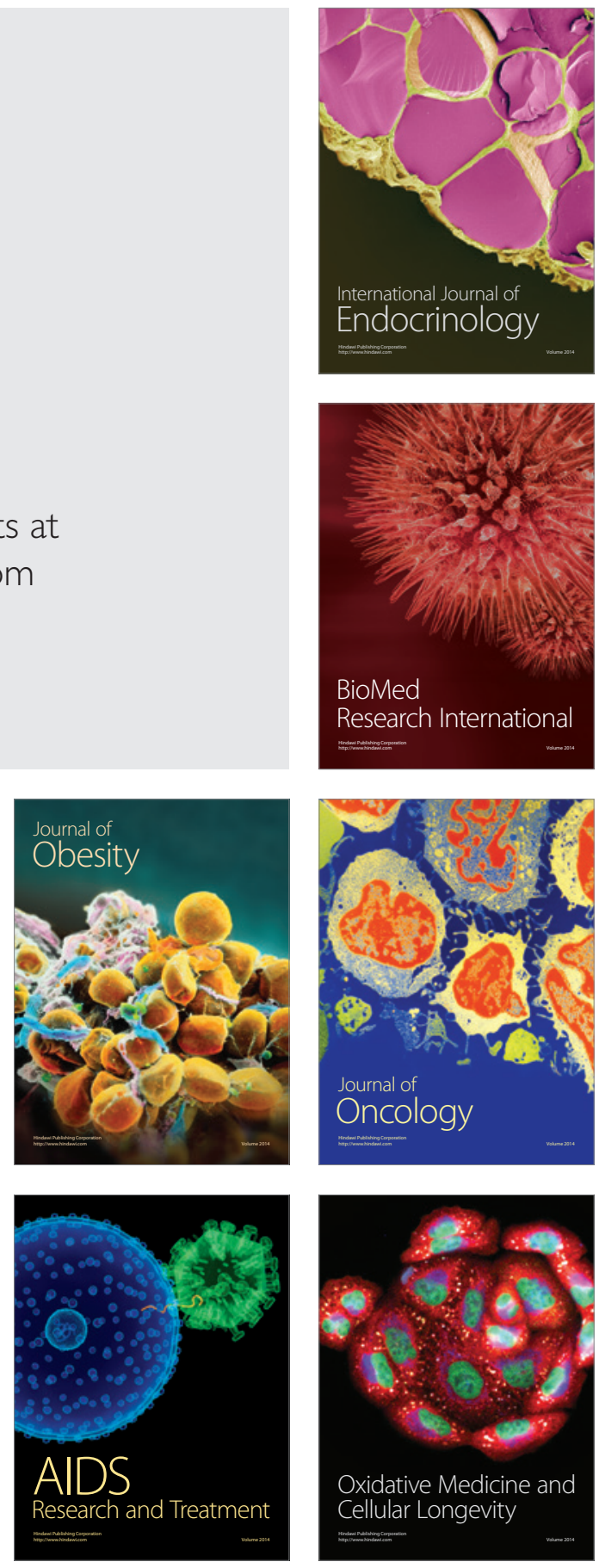